\title{
ANALISIS PENERAPAN PAJAK PERTAMBAHAN NILAI PADA PT. NENGGAPRATAMA INTERNUSANTARA
}

\author{
Andromedha Daud ${ }^{1}$, Harijanto Sabijono ${ }^{2}$, Sonny Pangerapan ${ }^{3}$ \\ ${ }^{1,2,3}$ Jurusan Akuntansi, Fakultas Ekonomi dan Bisnis, Universitas Sam Ratulangi, Jl. Kampus Bahu, Manado, \\ 95115, Indonesia \\ E-mail : ando.daud@gmail.com
}

\begin{abstract}
Tax is one of the very potential and quite dominant revenue because it has the function of budget and regulations. Taxation in which there is a VAT element is also part of the government's fiscal policy because one type of tax imposed by the government is Value Added Tax (VAT). The purpose of this study is to determine the application of Value Added Tax conducted by PT. Nenggapratama Internusantara. Based on the results of the research, the Application of Value Added Tax PT. Nenggapratama Internusantara is in conformity with Law no. 42 of 2009. The accounting treatment of Value Added Tax by PT. Nenggapratama Internusantara as a taxable entrepreneur is in accordance with Law no. 42 of 2009 which is $10 \%$ for domestic delivery.
\end{abstract}

Keywords: Value Added Tax (VAT), Input Tax, Output Tax

\section{PENDAHULUAN}

Sumber pendapatan negara salah satunya adalah dari pajak, menurut UUD 1945 Pasal 23 ayat 2 disebutkan segala pajak untuk keperluan negara berdasarkan UUD. Undang-undang Pajak adalah undang-undang yang mengatur para wajib pajak dan fiskus untuk melakukan kewajibannya. Pajak adalah kontribusi wajib kepada negara yang terutang oleh orang pribadi atau badan yang bersifat memaksa berdasarkan undang-undang, dengan tidak mendapatkan imbalan secara langsung dan digunakan untuk keperluan negara bagi sebesar-besarnya kemakmuran rakyat (UU No. 16 Tahun 2009 Pasal 1 Ayat 1).

Berdasarkan fungsinya pajak sendiri terbagi menjadi 2 (dua) fungsi yaitu fungsi Anggaran (Budgetair) dan fungsi Mengatur (Regulerend). Fungsi Anggaran membuat pajak menjadi sumber dana bagi pemerintah untuk membiayai pengeluaran-pengeluarannya, sedangkan fungsi mengatur menjadikan pajak sebagai alat untuk melaksanakan kebijakan pemerintah dalam bidang sosial dan ekonomi (Mardiasmo, 2016: 4). Setiap pergantian masa pemerintahan bahkan di setiap tahun bisa terjadi perubahan kebijakan khususnya untuk perpajakan dimana perubahan yang terjadi diharapkan akan menaikkan pendapatan dari pajak. Sektor perpajakan sendiri memiliki beberapa bagian dan berdasarkan pengelolaannya maka pajak dibagi menjadi 2 (dua) yaitu pajak pusat dan pajak daerah.

Pajak Pertambahan Nilai (PPN) adalah pajak yang dikenakan atas setiap pertambahan nilai dari barang atau jasa dalam peredarannya dari produsen ke konsumen. Dasar hukum utama yang digunakan untuk penerapan PPN di Indonesia adalah UU No. 42 Tahun 2009. PPN merupakan jenis pajak tidak langsung, PPN tersebut disetor oleh pedagang yang bukan penanggung pajak atau dengan kata lain, penanggung pajak atau konsumen akhir tidak menyetorkan langsung pajak yang menjadi tanggungannya. Perhitungan, pencatatan, pembayaran, dan pelaporan PPN ada pada pihak pedagang atau produsen sehingga muncul istilah Pengusaha Kena Pajak (PKP), dalam perhitungan PPN yang harus disetor oleh PKP (dikenal istilah Pajak Keluaran dan Pajak Masukan). 
PT. Nenggapratama Internusantara adalah Perusahaan yang bergerak di bidang barang dan jasa. Kegiatan penjualan barang dagang yang dilakukan adalah sebagai penjual unit kendaraan, dan penjual suku cadang (sparepart) kendaraan. Di samping itu perusahaan ini menyediakan jasa servis kendaraan, setiap unit kendaraan yang mengalami gangguan atau kerusakan untuk diperbaiki melalui jasa service ini. Untuk setiap penyerahan BKP/JKP yang dilakukan perusahaan dalam setiap pekerjaannya, perusahaan ini harus melakukan pembayaran Pajak Pertambahan Nilai (PPN), dan sebagai perusahaan yang bergerak dalam bidang penjualan barang dan jasa, penerapan Pajak Pertambahan Nilai mulai dari perhitungan, pencatatan, penyetoran dan pelaporan harus dilakukan sesuai dengan ketentuan undang-undang yang berlaku.

\section{TINJAUAN PUSTAKA}

\subsection{Pengertian Akuntansi}

Menurut definisi dari American Accounting Association yang dikutip oleh Sadeli (2015:2) menjelaskan bahwa akuntansi adalah suatu proses pengidentifikasian (pengkajian), pengukuran dan pengkomunikasikan informasi ekonomi untuk membantu para pemakai informasi dalam membuat pendapat-pendapat dan keputusan-keputusan.

\subsection{Definisi Pajak}

Menurut Dr. Soeparman Soemahamidjaja: "Pajak ialah iuran wajib, berupa uang atau barang, yang dipungut oleh penguasa berdasarkan norma-norma hukum, guna menutup biaya produksi barang-barang dan jasa-jasa kolektif dalam mencapai kesejahteraan umum".

\subsection{Pajak Pertambahan Nilai}

\subsubsection{Definisi Pajak Pertambahan Nilai}

Menurut Supramono (2015: 88) Pajak Pertambahan Nilai (PPN) adalah pajak yang dikenakan atas konsumsi di dalam daerah pabean, baik konsumsi barang kena pajak atau jasa kena pajak. PPN termasuk jenis pajak tidak langsung, yang berarti pajak tersebut disetor oleh pihak lain (pedagang) yang bukan penanggung pajak atau dengan kata lain, penanggung pajak (konsumen akhir) tidak menyetorkan langsung pajak yang tertanggung.

\subsubsection{Barang Kena Pajak (BKP) dan Jasa Kena Pajak (JKP)}

Barang kena pajak adalah barang berwujud, yang menurut sifat atau hukumnya dapat berupa barang bergerak atau barang tidak bergerak dan barang tidak berwujud yang dikenakan pajak berdasarkan UU No. 8 Tahun 1983 Pasal 1 ayat 2 dan 3. Semua barang hanya memiliki 2 dimensi, yaitu barang berwujud dan barang tidak berwujud, tidak ada dimensi ketiga. Barang berwujud juga hanya terdiri atas barang bergerak dan berang tidak bergerak, tidak ada bentuk yang ketiga. Dari pernyataan di atas, dapat disimpulkan bahwa semua barang termasuk ke dalam BKP, kecuali barang-barang yang ditentukan lain oleh undang-undang.

\subsubsection{Pengusaha Kena Pajak (PKP)}

Berdasarkan pasal 1 angka 15 UU PPN 1984 yang dikutip oleh Pohan (2016: 68) mengatakan Pengusaha Kena Pajak (PKP) adalah pengusaha yang melakukan penyerahan BKP atau penyerahan JKP yang dikenai pajak, tidak termasuk pengusaha kecil, kecuali pengusaha kecil tersebut memilih untuk dikukuhkan menjadi PKP sesuai pasal 3 (PMK 68/PM K.03/2013).

\subsubsection{Objek Pajak Pertambahan Nilai}

Pajak Pertambahan Nilai adalah pajak atas setiap pembelian barang kena pajak atau pemanfaatan jasa kena pajak baik di dalam wilayah Indonesia maupun di luar Indonesia (pabean). Pajak Pertambahan Nilai (PPN) juga merupakan pajak tidak langsung dan pajak atas konsumsi dalam negeri. 


\subsubsection{Faktur Pajak}

Menurut Prastowo (2016 : 69) Faktur Pajak adalah bukti pungutan pajak yang dibuat PKP yang melakukan penyerahan BKP atau JKP atau bukti pungutan pajak karena impor BKP yang digunakan oleh Direktorat Jenderal Bea dan Cukai. PPN yang dipungut berfungsi sebagai pajak keluaran bagi penjual dan pajak masukan bagi pembeli.

\subsubsection{Dasar Pengenaan Pajak dan Mekanisme Pengenaan PPN}

Dasar pengenaan pajak adalah dasar yang dipakai untuk menghitung pajak yang terutang, berupa: jumlah harga jual, penggantian, nilai impor, nilai ekspor, atau nilai lain yang ditetapkan dengan Keputusan Menteri Keuangan (KMK No. 251/KMK 04/02).

\subsubsection{Tarif Pajak Pertambahan Nilai}

Tarif PPN menurut UU No.42 Tahun 2009 Pasal 7:

1. Tarif PPN (Pajak Pertambahan Nilai) adalah 10\% (sepuluh persen).

2. Tarif PPN (Pajak Pertambahan Nilai) sebesar 0\% (nol persen) diterapkan atas:

a. Ekspor Barang Kena Pajak Berwujud ;

b. Ekspor Barang Kena Pajak Tidak Berwujud ;

c. Ekspor Jasa Kena Pajak.

3. Tarif pajak sebagaimana yang dimaksud pada ayat 1 (satu) dapat berubah menjadi paling rendah 5\% (lima persen) dan paling tinggi sebesar 15\% (lima belas persen) sebagaimana diatur oleh Peraturan Pemerintah.

\subsubsection{Saat Terutang Pajak dan Tempat Terutang Pajak}

Pajak terutang pada saat penyerahan BKP atau JKP, Impor BKP, pemanfaatan BKP tidak berwujud dari luar daerah pabean di dalam daerah pabean, pemanfaatan JKP dari luar daerah pabean, ekspor BKP berwujud, ekspor BKP tidak berwujud, ekspor JKP, dan pembayaran, pembayaran diterima sebelum penyerahan BKP atau sebelum penyerahan JKP. Tempat terutang pajak antara lain sebagai berikut :

1. Untuk penyerahan BKP/JKP yaitu tempat tinggal, tempat kedudukan, tempat kegiatan usaha dan tempat lain.

2. Dalam hal impor, terutangnya pajak terjadi di tempat Barang Kena Pajak dimasukkan dan dipungut melalui Direktorat Jenderal Bea dan Cukai.

3. Orang pribadi atau badan yang memanfaatkan BKP Tidak Berwujud dan atau JKP dari luar daerah pabean di dalam daerah pabean terutang pajak di tempat tinggal atau tempat kedudukan dan atau tempat kegiatan usaha.

4. Untuk kegiatan membangun sendiri oleh PKP yang dilakukan tidak dalam lingkungan perusahaan atau pekerjaannya atau bukan oleh PKP, di tempat bangunan tersebut didirikan.

\subsection{Pembetulan Surat Pemberitahuan Pajak}

Berdasarkan Undang-Undang No. 28 Tahun 2007 Pasal 8, Wajib Pajak dengan kemauan sendiri dapat membetulkan Surat Pemberitahuan yang telah disampaikan dengan menyampaikan pernyataan tertulis, dengan syarat Direktur Jenderal Pajak belum melakukan tindakan pemeriksaan.

Wajib Pajak dengan kesadaran sendiri dapat mengungkapkan dalam laporan tersendiri tentang kekeliruan atau ketidakbenaran pengisian Surat Pemberitahuan yang telah disampaikan sesuai keadaan yang sebenarnya, yang dapat mengakibatkan :

1. Pajak-pajak yang masih harus dibayar menjadi lebih besar atau lebih kecil.

2. Rugi berdasarkan ketentuan perpajakan menjadi lebih kecil atau lebih besar.

3. Jumlah harta menjadi lebih besar atau lebih kecil.

4. Jumlah modal menjadi lebih besar atau lebih kecil.

\subsection{Perlakuan Akuntansi PPN}

Akuntansi memiliki tahap-tahap dan cara kerja yang telah diatur untuk menghasilkan sebuah laporan yang baik dan mudah dimengerti. Perlakukan akuntansi sendiri merupakan 
perlakuan terhadap transaksi-transaksi yang berhubungan dengan PPN maupun PPnBM. Tata cara umum Pajak Pertambahan Nilai (PPN) adalah pengusaha kena pajak dapat mengurangkan atau mengkreditkan pajak masukan dalam suatu masa dengan pajak keluaran dalam masa pajak yang sama.

Pihak yang dikenakan kewajiban untuk memungut Pajak Pertambahan Nilai (PPN) adalah Pengusaha Kena Pajak (PKP). PKP diwajibkan untuk memungut PPN ketika melakukan penjualan barang atau jasa.Bagi PKP PPN yang dipungut ini disebut Pajak Keluaran (PK). Sebaliknya, ketika PKP membeli barang atau jasa, PKP mungkin juga dipungut PPN oleh penyalur atau penyedia jasanya. Dalam satu bulan, seluruh pajak keluaran dikurangi dengan seluruh pajak masukan. Jika selisihnya positif di mana PK lebih besar dari PM, PKP harus menyetorkan jumlah tersebut ke kas negara dengan menggunakan Surat Setoran Pajak (SSP). Jika selisihnya negatif, maka terjadi lebih bayar. PKP bisa memperhitungkan kelebihan bayar ini dengan perhitungan bulan berikutnya, proses ini disebut kompensasi. Bisa juga PKP meminta kelebihan bayar tersebut, proses ini disebut restitusi.

Pada saat pemungutan PPN oleh PKP, yang harus diingat adalah pajak keluaran yang dipungut pada hakikatnya adalah milik negara sehingga pajak keluaran merupakan hutang bagi PKP. Sebaliknya PPN keluaran, PPN masukan pada hakikatnya adalah piutang karena PPN yang dibayar dapat diklaim ke negara, seluruh pajak keluaran dan pajak masukan selama sebulan akan diperhitungkan dalam SPT Masa PPN. Jika PK lebih besar dari PM maka PKP masih harus membayar selisihnya ke kas negara, akun PM ada di bagian kredit dalam jurnal akuntansinya.

\section{METODE PENELITIAN}

\subsection{Jenis Data, dan Sumber Data}

Pada umumnya yang menjadi bahan pertimbangan dalam memilih masalah penelitian adalah jenis data dan ketersediaan sumber data. Data adalah sebuah catatan atas kumpulan fakta yang berisi informasi untuk penganbilan sebuah keputusan, dalam penelitian ini tentunya diperlukan data yang berhubungan dengan permasalahan yang hadapi, data juga dapat diperoleh dari keterangan-keterangan atau dari suatu penelitian ataupun melalui referensi yang dapat digunakan dalam menganalisis permasalahan yang dihadapi. Ada 2 (dua) jenis data yang digunakan pada pada penelitian ini yaitu menggunakan jenis data kualitatif dan kuantitaif

\subsubsection{Jenis Data}

Menurut Kuncoro (2013: 145), jenis data terbagi 2 (dua) yaitu :

1. Data Kualitatif, yaitu data yang berisi kondisi perusahaan seperti latar belakang perusahaan, struktur organisasinya, tujuan perusahaan, rencana perusahaan, kebijakan perusahaan. Data tersebut dapat diperoleh secara lisan maupun tulisan.

2. Data Kuantitatif, yaitu data yang berbentuk dokumen, daftar atau angka-angka yang dapat dihitung berupa laporan keuangan perusahaan.

\subsubsection{Sumber Data}

Sumber data yang digunakan dalam penelitian ini adalah :

1. Data primer adalah data yang dikumpulkan sendiri oleh peneliti langsung dari sumber pertama. Dalam hal ini peneliti berkesempatan untuk melakukan wawancara dengan petugas perusahaan.

2. Data sekunder adalah data yang diterbitkan atau digunakan oleh organisasi yang bukan pengolahnya. Dalam hal ini data sekunder yang digunakan adalah dokumendokumen penyetoran dan pelaporan PPN.

\subsection{Prosedur Penelitian}

Prosedur yang dilakukan dalam penelitian ini adalah : 
1. Mengidentifikasikan latar belakang masalah dalam penelitian ini.

2. Merumuskan masalah dalam penelitian ini.

3. Mencari literature-literatur yang terkait dalam penelitian ini.

4. Mengumpulkan data-data yang terkait dalam penelitian di PT. Nenggapratama Internusantara.

5. Mengelolah dan menganalisis data yang sudah diperoleh.

Menarik kesimpulan dan memberikan saran berdasarkan pembahasan dalam penelitian ini.

\subsection{Metode Pengumpulan Data}

Prosedur penelitian adalah sebagai berikut :

1. Persiapan

2. Observasi

3. Wawancara

4. Penelitian dan Pembahasan

5. Menarik Kesimpulan

\subsection{Metode Pengumpulan Data}

Metode pengumpulan data yang digunaka dalam penelitian ini adalah sebagai berikut:

1. Studi Pustaka

2. Studi Lapangan:
a. Wawancara
b. Observasi
c. Dokumen

\subsection{Teknik Analisis}

Dalam usaha untuk dapat memperoleh data dan informasi yang berkenaan dengan penelitian ini, maka teknik analisis untuk memecahkan permasalahan sebagai berikut :

1. Mengumpulkan dan menyusun informasi yang telah diperoleh untuk memperoleh gambaran umum tentang objek penelitian tersebut dimulai dari profil, struktur organisasi, dan kegiatannya.

2. Mengumpulkan data berupa dokumentasi yang berkaitan dengan pencatatan PPN dan pelaporan lain yang terkait dengan penelitian.

3. Mengambil landasan teori yang berhubungan dengan masalah yang diteliti yaitu UU No. 42 Tahun 2009 tentang Pajak Pertambahan Nilai (PPN).

4. Melakukan analisis perhitungan, pencatatan, pembayaran dan pelaporan Pajak Pertambahan Nilai (PPN) berdasarkan landasan teori di atas.

5. Menarik suatu kesimpulan serta saran-saran mengenai penerimaan dan pelaporan Pajak Pertambahan Nilai (PPN).

\section{HASIL PENELITIAN DAN PEMBAHASAN}

\subsubsection{Analisis Perhitungan Pajak Pertambahan Nilai (PPN)}

Sesuai peraturan yang ada yaitu UU No.42 tahun 2009 pasal 7 yang menentukan tarif PPN adalah 10\% (sepuluh persen), sedangkan tarif PPN sebesar 0\% (nol persen) diterapkan atas ekspor Barang Kena Pajak Berwujud, ekspor Barang Kena Pajak Tidak Berwujud, ekspor Jasa Kena Pajak. Adapun tarif pajak sebagaimana yang sudah diatur 10\% (sepuluh persen) untuk setiap Barang Kena Pajak (BKP)/Jasa Kena Pajak (JKP), dapat berubah menjadi paling rendah 5\% (lima persen) dan paling tinggi sebesar 15\% (lima belas persen) sebagaimana diatur oleh Peraturan Pemerintah.

Sesuai data yang didapat dari hasil penelitian yang dilakukan, di PT. Nenggapratama Internusantara maka didapati sejumlah transaksi yang terjadi selama tahun 2015. Dalam melakukan penghitungan besarnya PPN yang harus di setor atau yang disebut PPN Keluaran dan juga PPN yang harus dipungut perusahaan atau yang disebut dengan PPN Masukan maka 
perusahaan pun melakukan perhitungan berdasarkan peraturan yaitu Dasar Pengenaan Pajak dikalikan dengan tarif pajak sebesar $10 \%$

\subsubsection{Penyetoran Pajak Pertambahan Nilai (PPN)}

Dalam setiap Masa Pajak Pertambahan Nilai, wajib pajak berkewajiban melakukan penyetoran besarnya Pajak Pertambahan Nilai yang kurang bayar pada kas negara, ataupun melakukan restitusi atau kompensasi pada masa pajak berikutnya apabila terjadi lebih bayar atas Pajak Pertambahan Nilai. Wajib pajak melakukan penyetoran Pajak Pertambahan Nilai yang kurang kayar dengan menggunakan Surat Setoran Pajak kepada Kantor Pelayanan Pajak Pratama tempat wajib pajak dikukuhkan sebagai Pengusaha Kena Pajak.

\subsubsection{Pelaporan Pajak Pertambahan Nilai (PPN)}

Berdasarkan Undang-undang No. 42 Tahun 2009, Surat Pemberitahuan Masa Pajak Pertambahan Nilai disampaikan paling lama akhir bulan berikutnya setelah berakhirnya masa pajak. Apabila Perusahaan terlambat dalam melakukan pelaporan SPT Masa PPN, maka perusahaan akan dikenakan sanksi sebesar Rp. 500.000,00 sesuai dengan Undang-undang No. 28 Tahun 2007 tentang Ketentuan Umum dan Tata Cara Perpajakan pasal 7 ayat 1. SPT Masa PPN untuk PT. Nenggapratama Internusantara teridiri dari:

1. Formulir 1111 : SPT Masa PPN adalah Induk SPT Masa PPN

2. Formulir 1111AB : Rekapitulasi Penyerahan dan Perolehan adalah Lampiran SPT Masa PPN (memuat keterangan rekapitulasi penyerahan, perolehan dan penghitungan Pajak Masukan yang dapat dikreditkan)

3. File CSV : Perincian transaksi jual-beli oleh perusahaan dalam bentuk softcopy yang disimpan dalam flashdisc dengan format file CSV.

\subsection{Pembahasan}

\subsubsection{Perhitungan PPN}

Sesuai data yang didapat dari hasil penelitian yang dilakukan, di PT. Nenggapratama Internusantara maka didapati sejumlah transaksi yang terjadi selama tahun 2015. Dalam melakukan penghitungan besarnya PPN yang harus di setor atau yang disebut PPN Keluaran dan juga PPN yang harus dipungut perusahaan atau yang disebut dengan PPN Masukan maka perusahaan pun melakukan perhitungan berdasarkan peraturan yaitu Dasar Pengenaan Pajak dikalikan dengan tarif pajak sebesar $10 \%$.

\subsubsection{Penyetoran PPN}

Sesuai data yang didapat dari hasil penelitian yang dilakukan, di PT. Nenggapratama Internusantara Penyetoran PPN adalah nilai Kurang Bayar dari PPN Keluaran dikurangi PPN Masukan dan Kompensasi masa pajak sebelumnya.

Tabel 1 Penyetoran PPN Pada Pembetulan akhir Tahun 2015

\begin{tabular}{ccrccc}
\hline NO & MASA PAJAK & $\begin{array}{c}\text { KURANG/(LEBIH) } \\
\text { BAYAR }\end{array}$ & $\begin{array}{c}\text { TANGGAL } \\
\text { PENYETORAN }\end{array}$ & PEMB. & KETERANGAN \\
\hline 1 & JANUARI & $(212,658,529)$ & - & 1 & SESUAI \\
2 & FEBRUARI & $248,763,321$ & $1-$ Sep-2015 & 1 & TIDAK SESUAI \\
3 & MARET & $(414,074,925)$ & - & 0 & SESUAI \\
4 & APRIL & $(1,138,811)$ & - & 0 & SESUAI \\
5 & MEI & $(72,805,637)$ & - & 0 & SESUAI \\
6 & JUNI & $(65,781,371)$ & - & 0 & SESUAI \\
7 & JULI & $(14,353,155)$ & - & 0 & SESUAI \\
8 & AGUSTUS & $6,999,008$ & $29-$ Sep-2015 & 0 & SESUAI \\
9 & SEPTEMBER & $(8,718,493)$ & - & 1 & SESUAI \\
10 & OKTOBER & $(8,720,770)$ & - & 0 & SESUAI \\
11 & NOVEMBER & $(19,027,043)$ & - & 1 & SESUAI \\
12 & DESEMBER & $(330,035,830)$ & - & 2 & SESUAI \\
\hline \multicolumn{7}{r}{} & JUMLAH & $\mathbf{( 8 9 1 , 5 5 2 , 2 3 5 )}$ & & &
\end{tabular}


Berdasarkan Tabel 1, dapat dilihat penyetoran Pajak Pertambahan Nilai selama tahun 2015, PT. Nenggapratama Internusantara menyetorkan selisih PPN Kurang Bayar senilai Rp255.762.329,00 pada masa pajak Februari dan Agustus tetapi penyetoran pada masa pajak Februari terlambat disetorkan sehingga, perusahaan wajib membayar sanksi administrasi berupa denda sesuai dengan peraturan Undang-Undang No. 28 Tahun 2007 yaitu sebesar 2\% per bulan dari nilai PPN yang terutang oleh karena perusahaan melakukan pembetulan SPT Masa PPN. Untuk masa pajak bulan lainnya tidak dicatumkan tanggal penyetoran yang disebabkan karena perusahaan mengalami kondisi lebih bayar, dan untuk nilai selisih dari PPN lebih bayar PT. Nenggapratama Internusantara mengkompensasikan nilai tersebut ke dalam masa pajak selanjutnya.

\subsubsection{Pelaporan SPT Masa PPN}

Berdasarkan Undang-undang No. 42 Tahun 2009, Surat Pemberitahuan Masa Pajak Pertambahan Nilai disampaikan paling lama akhir bulan berikutnya setelah berakhirnya masa pajak. Apabila Perusahaan terlambat dalam melakukan pelaporan SPT Masa PPN, maka perusahaan akan dikenakan sanksi sebesar Rp. 500.000,00 sesuai dengan Undangundang No. 28 Tahun 2007 tentang Ketentuan Umum dan Tata Cara Perpajakan pasal 7 ayat 1. SPT Masa PPN untuk PT. Nenggapratama Internusantara teridiri dari:

1. Formulir 1111 : SPT Masa PPN adalah Induk SPT Masa PPN

2. Formulir 1111AB : Rekapitulasi Penyerahan dan Perolehan adalah Lampiran SPT Masa PPN (memuat keterangan rekapitulasi penyerahan, perolehan dan penghitungan Pajak Masukan yang dapat dikreditkan)

3. File CSV : Perincian transaksi jual-beli oleh perusahaan dalam bentuk softcopy yang disimpan dalam flashdisc dengan format file CSV.

Tabel 2 Pelaporan PPN Pada Pembetulan 0 (Normal)

\begin{tabular}{ccrcc}
\hline NO & MASA PAJAK & $\begin{array}{c}\text { KURANG/(LEBIH) } \\
\text { BAYAR }\end{array}$ & $\begin{array}{c}\text { TANGGAL } \\
\text { PELAPORAN }\end{array}$ & KETERANGAN \\
\hline 1 & JANUARI & $(143,550,642)$ & $27-F e b-2015$ & SESUAI \\
2 & FEBRUARI & $(1,281,649)$ & $17-$ Apr-2015 & TIDAK SESUAI \\
3 & MARET & $(414,074,925)$ & $3-$ Apr-2015 & SESUAI \\
4 & APRIL & $(1,138,811)$ & $7-$ Mei-2015 & SESUAI \\
5 & MEI & $(65,781,371)$ & $9-J u l-2015$ & SESUAI \\
6 & JUNI & $(14,353,155)$ & $8-A g u-2015$ & SESUAI \\
7 & JULI & $6,999,008$ & $30-$ Sep-2015 & SESUAI \\
8 & AGUSTUS & NIHIL & $30-$ Okt-2015 & SESUAI \\
9 & SEPTEMBER & $(8,720,770)$ & $4-$ Nov-2015 & SESUAI \\
10 & OKTOBER & NIHIL & $16-$ Des-2015 & SESUAI \\
11 & NOVEMBER & $(1,064,085,915)$ & 29-Jan-2016 & SESUAI \\
12 & DESEMBER & $(\mathbf{1 , 7 7 8 , 7 9 3 , 8 6 7 )}$ & & \\
\hline
\end{tabular}

Berdasarkan Tabel 2, dapat dilihat bahwa pelaporan Pajak Pertambahan Nilai pada masa pajak Februari 2015, PT. Nenggapratama Internusantara terlambat dalam melaporkan SPT Masa Pajak Pertambahan Nilai sehingga, perusahaan wajib membayar sanksi administrasi berupa denda sesuai dengan peraturan Undang-Undang No. 28 Tahun 2007 yaitu Rp500.000,00. Berdasarkan Tabel 2, dapat dilihat juga bahwa terdapat beberapa masa pajak yang pelaporan nilai PPNnya Nihil yaitu pada masa pajak September dan November oleh karena perusahaan mencoba agar tidak terlambat dalam melaporkan SPT Masa PPNnya dan terhindar dari sanksi administrasi, tetapi perusahaan telah melakukan pembetulan pada masa pajak yang terlapor nihil dapat dilihat pada Tabel 3. 


\begin{tabular}{|c|c|c|c|c|c|}
\hline \multicolumn{6}{|c|}{ Tabel 3 Pelaporan PPN Pada Pembetulan akhir } \\
\hline NO & MASA PAJAK & $\begin{array}{c}\text { KURANG/(LEBIH) } \\
\text { BAYAR }\end{array}$ & $\begin{array}{c}\text { TANGGAL } \\
\text { PELAPORAN }\end{array}$ & PEMB. & KETERANGAN \\
\hline 1 & JANUARI & $(212,658,529)$ & 21-Sep-2015 & 1 & SESUAI \\
\hline 2 & FEBRUARI & $248,763,321$ & 21-Sep-2015 & 1 & TIDAK SESUAI \\
\hline 3 & MARET & $(414,074,925)$ & 3-Apr-2015 & 0 & SESUAI \\
\hline 4 & APRIL & $(1,138,811)$ & 7-Mei-2015 & 0 & SESUAI \\
\hline 5 & MEI & $(72,805,637)$ & 23-Jun-2015 & 0 & SESUAI \\
\hline 6 & JUNI & $(65,781,371)$ & 9-Jul-2015 & 0 & SESUAI \\
\hline 7 & JULI & $(14,353,155)$ & 8-Agu-2015 & 0 & SESUAI \\
\hline 8 & AGUSTUS & $6,999,008$ & 30-Sep-2015 & 0 & SESUAI \\
\hline 9 & SEPTEMBER & $(8,718,493)$ & 7-Jun-2016 & 1 & SESUAI \\
\hline 10 & OKTOBER & $(8,720,770)$ & 4-Nov-2015 & 0 & SESUAI \\
\hline 11 & NOVEMBER & $(19,027,043)$ & 7-Jun-2016 & 1 & SESUAI \\
\hline \multirow[t]{2}{*}{12} & DESEMBER & $(330,035,830)$ & 29-Mar-2016 & 2 & SESUAI \\
\hline & JUMLAH & $(891,552,235)$ & & & \\
\hline
\end{tabular}

Berdasarkan Tabel 3, dapat dilihat bahwa pada masa pajak bulan Maret, April, Mei, Juni, Juli, Agustus, dan Oktober tahun 2015, PT. Nenggapratama Internusantara telah melaporkan Pajak Pertambahan Nilai sesuai dengan ketentuan yang berlaku. Tetapi pada masa pajak Januari, September, November dan Desember tahun 2015 PT. Nenggapratama Internusantara terlambat dalam melaporkan Pajak Pertambahan Nilai oleh karena melakukan pembetulan SPT Masa PPN, tetapi tidak melanggar peraturan dan terhindar dari sanksi administrasi oleh karena pada pelaporan pembetulan normal perusahaan tidak terlambat dalam melaporkan PPN.

\section{KESIMPULAN DAN SARAN}

\subsection{Kesimpulan}

Berdasarkan penelitian yang dilakukan terhadap PT. Nenggapratama Internusantara maka dapat dikemukakan beberapa hal yang dapat disimpulkan antara lain sebagi berikut:

1. Di dalam perhitungan PPN pada PT. Nenggapratama Internusantara telah sesuai dengan Undang-Undang No.42 Tahun 2009, baik dalam PPN Keluaran maupun PPN Masukan.

2. Dalam hal penyetoran PPN, PT. Nenggapratama Internusantara terlambat dalam menyetorkan PPN pada masa pajak Februari sehingga perusahaan perusahaan wajib membayar sanksi administrasi berupa denda sesuai dengan peraturan UndangUndang No. 28 Tahun 2007 yaitu sebesar 2\% per bulan dari nilai PPN yang terutang oleh karena perusahaan melakukan pembetulan akhir pada SPT Masa PPN.

3. PT. Nenggapratama Internusantara sering mengalami kondisi PPN Lebih Bayar, dikarenakan nilai PPN Masukan lebih besar dari PPN Keluaran sehingga, perusahaan berhak untuk mengkompensasikan selisih PPN Lebih Bayar pada masa pajak berikutnya untuk dapat dikreditkan.

4. PT. Nenggapratama Internusantara dalam melaporkan SPT Masa PPN pada pembetulan normal tahun 2015, hanya sekali terlambat melaporkan SPT Masa PPN yaitu pada masa pajak Februari sehingga, perusahaan wajib membayar sanksi administrasi berupa denda sesuai dengan peraturan Undang-Undang No. 28 Tahun 2007 yaitu Rp500.000,00. Pada masa pajak September dan November perusahaan melaporkan Nihil untuk SPT Masa PPN oleh karena ketidaklengkapan data transaksi PPN sehingga, perusahaan melakukan pembetulan akhir untuk melaporkan nilai PPN yang sebenarnya 


\subsection{Saran}

Berdasarkan penelitian yang dilakukan terhadap PT. Nenggapratama Internusantara dapat dikemukakan beberapa saran sebagai berikut:

1. Perusahaan hendaknya selalu mengikuti segala perkembangan dan perubahan yang terjadi dalam peraturan perpajakan, karena peraturan dan ketentuan pajak seringkali berubah guna mempermudah proses perpajakan di Indonesia.

2. PT. Nenggapratama Internusantara hendaknya dalam melakukan penyetoran dan pelaporan PPN selalu memperhatikan kelengkapan faktur pajak baik faktur pajak penjualan sebagai Pajak Keluaran dan dan faktur pajak pembelian sebagai Pajak Masukan agar tidak terjadi kekeliruan baik dalam penyetoran maupun pelaporan, mengingat perusahaan bebarapakali melakukan pembetulan SPT Masa PPN.

3. PT. Nenggapratama Internusantara hendaknya dalam melakukan perhitungan Pajak Pertambahan Nilai lebih memperhatikan lagi nilai PPN yang dipungut, dikarenakan terdapat sejumlah selisih antara DDP dan PPN yang harus dipungut sendiri oleh perusahaan.

4. PT. Nenggapratama Internusantara hendaknya menyimpan dokumen-dokumen PPN secara rapih dan teratur sehingga dapat membantu dalam pemeriksaan.

5. Pihak PT. Nenggapratama Internusantara seharusnya dapat melakukan pengadministrasi dengan lebih baik agar PPN yang dilaporkan per bulan adalah PPN yang benar-benar terjadi baik PPN Masukan maupun PPN Keluaran, karena masih terdapat pelaporan yang nihil pada bulan September dan November karena data yang belum lengkap.

\section{DAFTAR PUSTAKA}

Allan S. Schenk, 2009. Worldwide Versus Territorial Tax Sistems: Comparison of Value Added Tax and Income Tax. Research Paper No. 09-27, Dec. 2009, Wayne State University Law School. (Diakses 30 April 2017)

Budiarto, Asztrid. 2016. Pedoman Praktis Membayar Pajak. Yogyakarta : Genesis Learning.

Chang Woon Nam, 2011.Measurement of Value-Added Tax Evasion in Selected EU Coutries on the Basis of National Account Data. Working Paper Series No. 431, Apr. 2011, CESifo (Center for Economic Studies and Ifo Institute); Ifo Institute, Germany; University of Applied Management (UAM). (Diakses 30 April 2017)

Mardiasmo, 2016.Perpajakan Edisi Revisi.Yogyakarta : Penerbit Andi.

Pohan, Chairil Anwar. 2016. Pedoman Lengkap Pajak Pertambahan Nilai. Jakarta : PT. Gramedia Pustaka Utama

Prastowo, Yustinus, Priyatma, Agu dan Nugraha, Yosep. 2016. Pintar Menghitung Pajak. Jakarta : Raih Asa Sukses.

Rebbeca Millar, 2012.The Future of Inderect Taxation: Recent Trends in VAT and GST Sistems Around the World - Australia. The Netherlands , pp. 21-96, Jun, 2012. The University of Sydney Law School.(Diakses 30 April 2017)

Sadeli, Lili M, Haji. 2015. Dasar - dasar akuntansi : cetakan 9. Jakarta : Bumi Aksara

Sari, Diana. 2013. Konsep Dasar Perpajakan. Bandung : PT. Refika Aditama

Samudra, Azhari Aziz. 2016. Perpajakan Indonesia : Keuangan, Pajak, dan Retribusi Daerah. Jakarta : PT. RajaGrafindo Persada.

Suharsono, Agus. 2015. Ketentuan Umum Perpajakan. Yogyakarta :Graha Ilmu

Sukardji, Untung 2015. Pokok - pokok Pajak Pertambahan Nilai Indonesia.Jakarta: PT. RajaGrafindo Persada 
Sumarsan, Thomas. 2017. Perpajakan Indonesia : Pedoman Perpajakan yang Lengkap berdasarkan Undang - Undang Terbaru. Jakarta : PT Indeks

Supramono dan Damayanti, Theresia Woro. 2015. Perpajakan Indonesia, Mekanisme dan perhitungan. Yogyakarta : Andi

TMbooks. 2013. Perpajakan - Esesi dan Aplikasi. Yogyakarta : CV. Andi Offset

Kuncoro. 2013. Mudah Memahami dan Menganalisis Indikatir Ekonomi. Yogyakarta: UPP STIM YKPN.

Wollela Abehodie Yesegat, 2008. Value Added Tax Administration in Ethiopia A Reflection of Problems. Vol. 6, No. 2, pp. 145-168, Aug. 2008, University of New South Wales.(Diakses 30 April 2017)

Yuyu Chen, 2015. The Effect of Investment Tax Incentives: Evidence From China's Value Added Tax Reform.Vol. 4, pp. 1-33, Jul. 2015. Peking University - Guanghua School of Management. (Diakses 30 April 2017) 